\title{
Effects of negative pressure assisted ventilation on dyspnoeic sensation and breathing pattern
}

\author{
T. Nishino, S. Isono, T. Ide
}

Effects of negative pressure assisted ventilation on dyspnoeic sensation and breathing pattern. T. Nishino, S. Isono, T. Ide. CERS Journals Ltd 1998.

ABSTRACT: Although negative pressure assisted ventilation with an assist-control mode may have a potential therapeutic role in the treatment of severe dyspnoea, the effects of negative pressure assisted ventilation with the assist-control mode on dyspnoea and breathing patterns have not been examined.

We examined the effects of negative pressure assisted ventilation with the assistcontrol mode on dyspnoea and breathing patterns produced by a combination of resistive loading and hypercapnia in nine healthy subjects breathing spontaneously. Subjects were asked to rate their sensation of respiratory discomfort using a visual analogue scale.

Negative pressure assisted ventilation caused a significant reduction in sensation of respiratory discomfort from a visual analogue scale score of 74 (55-91) (median (range)) before negative pressure assisted ventilation to 34 (15-53) during negative pressure assisted ventilation $(\mathbf{p}<0.01)$. During negative pressure assisted ventilation, there were significant changes in breathing patterns characterized by an increase in tidal volume and a decrease in respiratory frequency, while neither minute ventilation nor end-tidal carbon dioxide tension changed.

Our results indicate that negative pressure assisted ventilation with the assist-control mode is effective in relief of dyspnoea and that negative pressure assisted ventilation influences the control of breathing to minimize respiratory discomfort. Eur Respir J 1998; 12: 1278-1283.
Dept of Anaesthesiology, School of Medicine, Chiba University, Chiba, Japan.

Correspondence: T. Nishino

Dept of Anaesthesiology

School of Medicine

Chiba University

1-8-1 Inohanacho, Chuo-ku

Chiba $260-8670$

Japan

Fax: 81432262156

Keywords: Breathing patterns dyspnoea

negative pressure ventilation

Received: June 261998

Accepted after revision September 191998

This work is supported in part by a Grantin-Aid from the Ministry of Health and Welfare for the Second-term Comprehensive 10-year Strategy for Cancer Control.
Noninvasive assisted ventilation has become increasingly popular recently and has been used successfully in a variety of clinical situations, including weaning from mechanical ventilation and ventilatory support in patients with chronic obstructive pulmonary disease (COPD) [1-8]. Several modalities are now available for noninvasive assisted ventilation including positive pressure assisted ventilation (PPAV) and negative pressure assisted ventilation (NPAV), although PPAV in the form of pressure support (PS) is more popular than NPAV.

Severe dyspnoea is a devastating symptom in bedridden, terminally ill patients with both malignant and nonmalignant disease and is often difficult to palliate despite the availability of various modalities for patients with intractable dyspnoea [9].

Several studies [10-13] suggest that noninvasive PPAV is effective in relief of respiratory discomfort or dyspnoea while increasing alveolar ventilation. However, noninvasive PPAV has several drawbacks such as intolerance of the mask or poor adaptation to the mask, nasal dryness, ocular irritation, and gastric distention secondary to inability to maintain an open glottis [14]. For those patients with severe dyspnoea in whom PPAV is not the treatment of choice, NPAV may be an alternative technique.

Although NPAV may have a potential therapeutic role in the treatment of terminally ill patients with severe dyspnoea, several previous studies $[3,4,6]$ failed to demonstrate any clinical benefit with the use of NPAV. In these studies, NPAV was applied with the mode of controlled ventilation (control mode) in which tidal volume $(V \mathrm{~T})$ and respiratory frequency $(f R)$ were fixed. Such modes of ventilation may cause dysynchrony of the patients to ventilatory support, producing discomfort rather than comfort of the patients. Therefore, ventilatory support with the control mode may be one interpretation of unfavourable results.

In this study, we investigated, using a self-controlled design, the effects of NPAV with an assist-control mode on the relief of severe dyspnoea produced by hypercapnia and resistive loading in normal subjects. We also evaluated the effects of NPAV on the control of breathing by assessing changes in breathing patterns during NPAV since breathing pattern has been reported to affect the respiratory sensations [15].

\section{Methods}

This study protocol was approved by the Ethics Committee of Chiba University School of Medicine and informed consent was obtained from all subjects. Nine healthy volunteer subjects $25-50$ yrs of age were studied. None of the subjects had clinical evidence of respiratory, cardiovascular, or neuromuscular disorders. The research was carried out in accordance with the Declaration of Helsinki (1989) of the World Medical Association. 
Each subject was seated during the experiment and a plastic chest shell of appropriate size (Hayek Oscillator, No. 7 or No. 8) was positioned over the chest (fig. 1). Each subject breathed through a tightly fitting face mask connected to a pneumotachograph (CP-100; Allied Health Care Product, St. Louis, MO, USA), and then to a T-piece system. The mask was tested for air leaks by pressurizing to $\pm 20 \mathrm{cmH}_{2} \mathrm{O}$ and ensuring that the pressure held for $10 \mathrm{~s}$. Ventilatory airflow was measured with the pneumotachograph, and $V \mathrm{~T}$ was obtained by electrical integration of the inspired flow signal. Mask pressure ( $P$ mask) was measured with a pressure transducer (Transpac ${ }^{\circledR}$ IV; Abbott Critical Care Systems, Chicago, IL, USA). End-tidal carbon dioxide tension $\left(P\right.$ ET, $\left.\mathrm{CO}_{2}\right)$ was monitored with an infrared $\mathrm{CO}_{2}$ analyser (Aika® MEL RAS-41, Aika, Tokyo, Japan) through a port in the face mask. The sensation of dyspnoea in subjects was induced by a combination of resistive loading and hypercapnia: a plastic tube resistor $(4 \mathrm{~mm}$ in diameter and $200 \mathrm{~mm}$ in length) and a plastic tube $(50 \mathrm{~mm}$ in diameter and $150 \mathrm{~mm}$ in length: $295 \mathrm{~mL}$ in capacity) were placed between the face mask and the pneumotachograph. The experimental apparatus had a resistance of $45 \mathrm{cmH}_{2} \mathrm{O}$. $\mathrm{L}^{-1} \cdot \mathrm{s}^{-1}$ at a flow rate of $0.5 \mathrm{~L} \cdot \mathrm{s}^{-1}$ and the total instrumental dead space was $500 \mathrm{~mL}$ when the resistive loading and the external dead space were added.

Negative pressure ventilation was provided by a homemade ventilator consisting of three solenoid valves, a vacuum cleaner as a negative pressure generator, and a solenoid control unit (fig. 1). Closing and opening of the solenoid valves were triggered by the inspiratory flow signal at a threshold flow of $30 \mathrm{~mL} \cdot \mathrm{s}^{-1}$. The delay to reach the negative pressure for opening airways after triggering the solenoid valves was $<75 \mathrm{~ms}$ in the absence of air leaks. The delivered (extrathoracic) negative pressure (Pext) was measured with a pressure transducer (Uniflow, Baxter, Japan) and the negative pressure setting of the ventilator was adjusted to maintain a pressure between -45 and $-50 \mathrm{cmH}_{2} \mathrm{O}$. When air leakage occurred through the chest shell, the chest shell was repositioned so that $P$ ext remained constant. Airflow, VT, Pmask, PET, $\mathrm{CO}_{2}, P$ ext, and visual anal-

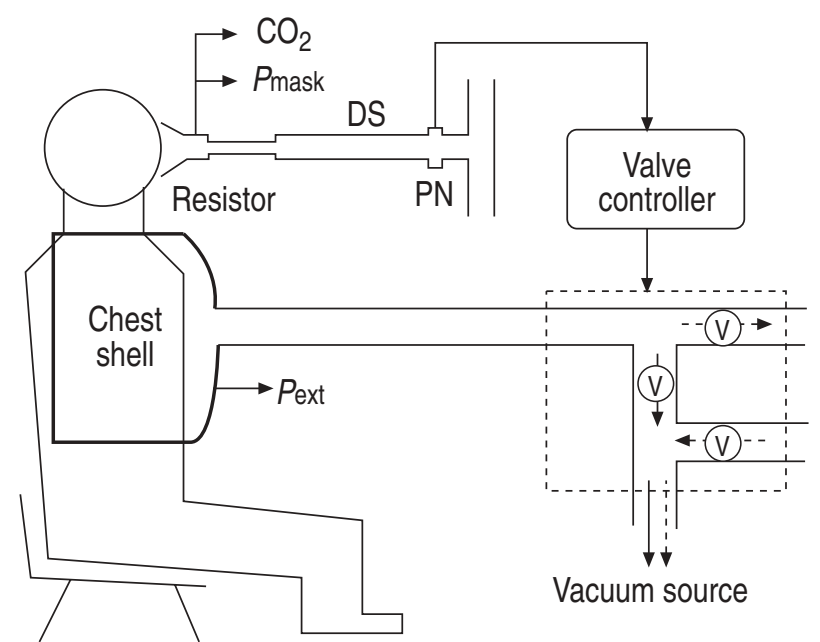

Fig. 1. - Schematic illustration of the experimental apparatus and ventilator. Pmask: mask pressure; Pext: extrathoracic pressure, i.e. the delivered negative pressure; DS: dead space; PN: pneumotachograph; (v): solenoid valve; $\longrightarrow$ : airflow during inspiration; $-\rightarrow$ : airflow during expiration. ogue scale (VAS) score all were recorded on a thermal array recorder (Omniace RT3424; NEC, Tokyo, Japan).

During the experiment, the subject was asked to rate the intensity of the sensation of respiratory discomfort using a VAS. The analogue scale consisted of a horizontal $20 \mathrm{~cm}$ line with 10 equally spaced markers. Subjects could control the position of the knob of the linear potentiometer along this line ranging $0-100$. The numerical value of 0 was given for the sensation of "not at all unpleasant" and 100 for the sensation of "intolerable." Respiratory discomfort was defined as "an unpleasant urge to breathe". No further clarification or definitions were given, and the subjects were not asked to distinguish different qualities or dimensions of the respiratory sensation.

Before the start of the main study, a preliminary experiment was performed to familiarize the subject with the apparatus, the sensation of breathing against the added load, and the use of the VAS. Subjects then had two 20min trials of loaded breathing. A 10-min rest period separated the two trials. In each of the trials, after application of the resistive load and respiratory dead space, $10 \mathrm{~min}$ were allowed for the establishment of a steady respiratory state and respiratory sensation while the subject breathed spontaneously without assisted ventilation (baseline period). The subject was instructed to continue the loaded breathing for 5 min through assisted ventilation (test period) while rating the magnitude of respiratory discomfort by VAS score, after which the loaded breathing continued for another 5 min without assisted ventilation (recovery period). At the end of the experiment, subjects were questioned about their breathlessness and other sensations. During the experiments, hyperoxia was maintained by passing $100 \%$ oxygen, with a total gas flow of $16 \mathrm{~L} \cdot \mathrm{min}^{-1}$, through the Tpiece.

The effect of assisted ventilation on respiratory sensation and breathing patterns were evaluated by comparing the values of ventilatory variable and VAS scores obtained from measurements at the last 1 min during the baseline, test, and recovery periods. Statistical analysis was performed by using the Wilcoxon signed-rank test and Friedman repeated measures of analysis of variance (ANOVA) on ranks, followed by Dunnet's test. Data are expressed as median (range). A p-value $<0.05$ was taken as the level of statistical significance.

\section{Results}

All subjects tolerated two 20-min trials of loaded breathing and completed the experimental protocol. Because there was no discernible difference in the responses to assisted ventilation between the two trials in any subject (table 1), the changes in respiratory variables during baseline, test and recovery periods obtained from these two trials were averaged and the mean values were used for comparison with different periods.

Immediately after the addition of the respiratory load, $V \mathrm{~T}$ and $\mathrm{PET}, \mathrm{CO}_{2}$ increased with a concomitant increase in VAS score. However, these changes gradually stabilized within $5 \mathrm{~min}$, and thereafter, breathing patterns as well as VAS scores remained nearly steady. Although there was an intersubject variability in breathing patterns, a combination of resistive loading and hypercapnia usually caused an increase in $V$ T without a change in inspiration time $(t \mathrm{I})$ and expiratory time $(\mathrm{t}$ E) (table 2$)$. 
Table 1. - Individual data on respiratory variables and visual analogue scale (VAS) score during the two trials of loaded breathing in all subjects

\begin{tabular}{|c|c|c|c|c|c|c|c|c|c|c|c|c|c|}
\hline \multirow[b]{2}{*}{$\begin{array}{l}\text { Subject } \\
\text { No. }\end{array}$} & \multirow[b]{2}{*}{$\begin{array}{l}\text { Trial } \\
\text { No. }\end{array}$} & \multicolumn{4}{|c|}{ Baseline } & \multicolumn{4}{|c|}{ Test } & \multicolumn{4}{|c|}{ Recovery } \\
\hline & & $\begin{array}{l}\mathrm{T} \\
\mathrm{L}\end{array}$ & $\begin{array}{c}f \mathrm{R} \\
\text { breaths.min-1 }\end{array}$ & $\begin{array}{l}P{\mathrm{ET}, \mathrm{CO}_{2}} \\
\mathrm{mmHg}\end{array}$ & $\overline{\text { VAS }}$ & $\begin{array}{l}V \mathrm{~T} \\
\mathrm{~L}\end{array}$ & $\begin{array}{c}f \mathrm{R} \\
\text { breaths.min-1 }\end{array}$ & $\begin{array}{l}P{\mathrm{ET}, \mathrm{CO}_{2}} \\
\mathrm{mmHg}\end{array}$ & $\overline{\text { VAS }}$ & $\begin{array}{l}V \mathrm{~T} \\
\mathrm{~L}\end{array}$ & $\begin{array}{c}f \mathrm{R} \\
\text { breaths.min-1 }\end{array}$ & $\begin{array}{l}P{\mathrm{ET}, \mathrm{CO}_{2}}_{2} \\
\mathrm{mmHg}\end{array}$ & VAS \\
\hline \multirow[t]{2}{*}{1} & 1 & 0.86 & 17.8 & 47.4 & 60 & 0.96 & 15.2 & 47.7 & 14 & 0.77 & 21.2 & 46.3 & 60 \\
\hline & 2 & 0.84 & 17.4 & 47.8 & 60 & 0.99 & 15.6 & 47.5 & 16 & 0.79 & 21.6 & 45.4 & 59 \\
\hline \multirow[t]{2}{*}{2} & 1 & 0.60 & 19.0 & 52.0 & 83 & 0.77 & 15.3 & 51.5 & 28 & 0.75 & 17.6 & 52.0 & 83 \\
\hline & 2 & 0.72 & 18.6 & 50.0 & 87 & 0.85 & 14.7 & 50.5 & 32 & 0.79 & 17.4 & 50.0 & 83 \\
\hline \multirow[t]{2}{*}{3} & 1 & 0.85 & 21.0 & 53.4 & 90 & 0.95 & 16.7 & 54.4 & 39 & 0.78 & 21.4 & 54.3 & 90 \\
\hline & 2 & 0.84 & 19.0 & 55.3 & 90 & 0.91 & 16.7 & 54.4 & 41 & 0.70 & 21.5 & 55.2 & 86 \\
\hline \multirow[t]{2}{*}{4} & 1 & 0.57 & 22.4 & 49.1 & 66 & 0.71 & 18.8 & 49.5 & 35 & 0.50 & 25.2 & 49.3 & 63 \\
\hline & 2 & 0.61 & 20.4 & 49.5 & 60 & 0.79 & 18.8 & 49.0 & 31 & 0.54 & 24.8 & 49.2 & 62 \\
\hline \multirow[t]{2}{*}{5} & 1 & 0.91 & 16.7 & 45.9 & 60 & 1.28 & 12.5 & 45.0 & 25 & 0.85 & 17.6 & 48.2 & 65 \\
\hline & 2 & 0.94 & 16.7 & 45.8 & 60 & 1.15 & 13.5 & 46.8 & 21 & 0.89 & 17.6 & 45.4 & 61 \\
\hline \multirow[t]{2}{*}{6} & 1 & 0.77 & 15.0 & 57.1 & 58 & 0.98 & 12.4 & 56.0 & 34 & 0.70 & 18.2 & 56.8 & 60 \\
\hline & 2 & 0.83 & 15.0 & 56.7 & 52 & 0.92 & 12.6 & 56.0 & 26 & 0.66 & 17.0 & 58.8 & 55 \\
\hline \multirow[t]{2}{*}{7} & 1 & 0.88 & 17.6 & 54.0 & 82 & 0.94 & 13.9 & 56.1 & 42 & 0.78 & 17.4 & 54.4 & 83 \\
\hline & 2 & 0.82 & 16.6 & 54.6 & 88 & 0.82 & 16.1 & 56.0 & 41 & 0.77 & 16.8 & 54.7 & 82 \\
\hline \multirow[t]{2}{*}{8} & 1 & 0.68 & 20.5 & 48.8 & 91 & 0.92 & 15.5 & 47.5 & 44 & 0.68 & 21.0 & 47.5 & 90 \\
\hline & 2 & 0.74 & 19.5 & 52.6 & 90 & 0.88 & 14.5 & 57.5 & 40 & 0.79 & 21.8 & 57.5 & 95 \\
\hline \multirow[t]{2}{*}{9} & 1 & 0.73 & 18.2 & 58.8 & 74 & 0.95 & 13.8 & 58.2 & 51 & 0.77 & 18.1 & 54.6 & 74 \\
\hline & 2 & 0.79 & 18.2 & 57.0 & 74 & 0.91 & 14.2 & 57.6 & 55 & 0.79 & 16.1 & 57.6 & 73 \\
\hline
\end{tabular}

$V \mathrm{~T}$ : tidal volume; $f \mathrm{R}$ : respiratory frequency; $P \mathrm{ET}, \mathrm{CO}_{2}$ : end-tidal carbon dioxide tension. $(0.133 \mathrm{kPa}=1 \mathrm{mmHg}$.)

Figure 2 shows an experimental record illustrating changes in breathing pattern and VAS score in response to application of assisted ventilation. At initiation of assisted ventilation, there was an increase in $V \mathrm{~T}$ with a concomitant decrease in VAS score. The increase in $V \mathrm{~T}$ always accompanied a decrease in $f R$, and these changes gradually stabilized within 4 min. Immediately after the cessation of assisted ventilation, there was a decrease in $V \mathrm{~T}$ with a concomitant increase in $f \mathrm{R}$ along with a gradual increment in VAS score that returned to the baseline level within $3 \mathrm{~min}$. Despite the changes in $V \mathrm{~T}$ and $f \mathrm{R}$ there was no remarkable change in $P$ ET, $\mathrm{CO}_{2}$ during assisted ventilation.

Changes in respiratory variables obtained in all subjects are summarized in table 2. Although there was a significant increase in $V \mathrm{~T}(\mathrm{p}<0.05)$ as well as a significant decrease in $f \mathrm{R}(\mathrm{p}<0.05)$ during assisted ventilation (test period), neither minute ventilation nor $P \mathrm{ET}, \mathrm{CO}_{2}$ changed significantly throughout the course of loaded breathing.

Changes in VAS scores during assisted ventilation are summarized in figure 3 . The values of VAS scores during baseline, test, and recovery periods were 74 (55-91) (median (range)), 34 (15-53), and 74 (58-93), respectively. The values during the test period were significantly smaller $(\mathrm{p}<$ 0.01 ) than those during the baseline and recovery periods.

\section{Discussion}

This study demonstrated that noninvasive NPAV with the assist-control mode is effective in relief of dyspnoeic sensation produced experimentally by a combination of resistive loading and hypercapnia in healthy subjects. In our study, hypercapnia and resistive loading are used in healthy subjects to model dyspnoea. This model may mimic the pathological conditions observed occasionally in patients with acute exacerbations of COPD or in patients with incurable cancer whose airway is obstructed by tumour. However, the dyspnoea experienced by these patients may result from the interaction of many factors including not only increased airway resistance and hypercapnia but also muscle fatigue, hypoxaemia, and bronchial inflammation. Thus, a simple extrapolation of this model to certain pathological conditions may not be entirely valid.

There is increasing evidence to suggest that noninvasive assisted ventilation has a role in managing patients with dyspnoea $[2,5,8,10-12]$, although many of the reports have been anecdotal in nature. Our results are compatible with these reports. By contrast, several other studies reported problems with patient acceptance and comfort during NPAV and showed no benefit for patients with dyspnoea

Table 2. - Changes in breathing patterns during unloaded and loaded breathing with or without negative pressure assisted ventilation

\begin{tabular}{|c|c|c|c|c|}
\hline & Unloaded & $\begin{array}{c}\text { Loaded } \\
\text { (baseline) }\end{array}$ & $\begin{array}{c}\text { Loaded } \\
\text { (test) }\end{array}$ & $\begin{array}{l}\text { Loaded } \\
\text { (recovery) }\end{array}$ \\
\hline$V \mathrm{~T} \mathrm{~L}$ & $0.61(0.46-0.74)$ & $0.80(0.59-0.93)^{* *}$ & $0.93(0.75-1.22)^{*}$ & $0.77(0.52-0.87)$ \\
\hline$t \mathrm{I} \mathrm{S}$ & $(1.2-2.2)$ & $(1.4-2.0)$ & $(1.5-2.4)$ & $(1.2-1.7)$ \\
\hline$t \mathrm{E} \mathrm{s}$ & $(1.2-2.4)$ & $(1.4-2.2)$ & $(1.6-2.8) *$ & $(1.2-2.2)$ \\
\hline$f_{\mathrm{R}}$ breaths $\cdot \min ^{-1}$ & $18.8 \quad(13.0-25.0)$ & $18.2 \quad(15.0-21.4)$ & $(12.0-18.8)^{*}$ & $17.6(17.1-25.0)$ \\
\hline$V^{\prime} \mathrm{E} \mathrm{L} \cdot \mathrm{min}^{-1}$ & $(7.9-13.9)$ & $13.8(12.0-17.0)^{* *}$ & 13.5 (11.9-15.4) & $13.6(12.0-16.7)$ \\
\hline$P$ ET, $\mathrm{CO}_{2} \mathrm{mmHg}$ & $39.8 \quad(35.0-44.2)$ & $51.0 \quad(45.9-57.9)^{* *}$ & $52.5 \quad(45.9-57.9)$ & $52.5 \quad(45.9-57.8)$ \\
\hline
\end{tabular}

Values are median (range). $V \mathrm{~T}$ : tidal volume; $t \mathrm{I}$ : inspiratory time; $t \mathrm{E}$ : expiratory time; $f \mathrm{R}:$ respiratory frequency; $V$ 'E: minute ventilation; $P \mathrm{ET}, \mathrm{CO}_{2}$ : end-tidal carbon dioxide tension. $*$ : $\mathrm{p}<0.05$, compared with the values during baseline; **: $\mathrm{p}<0.01$, compared with the values during unloaded breathing. $(0.133 \mathrm{kPa}=1 \mathrm{mmHg}$.) 


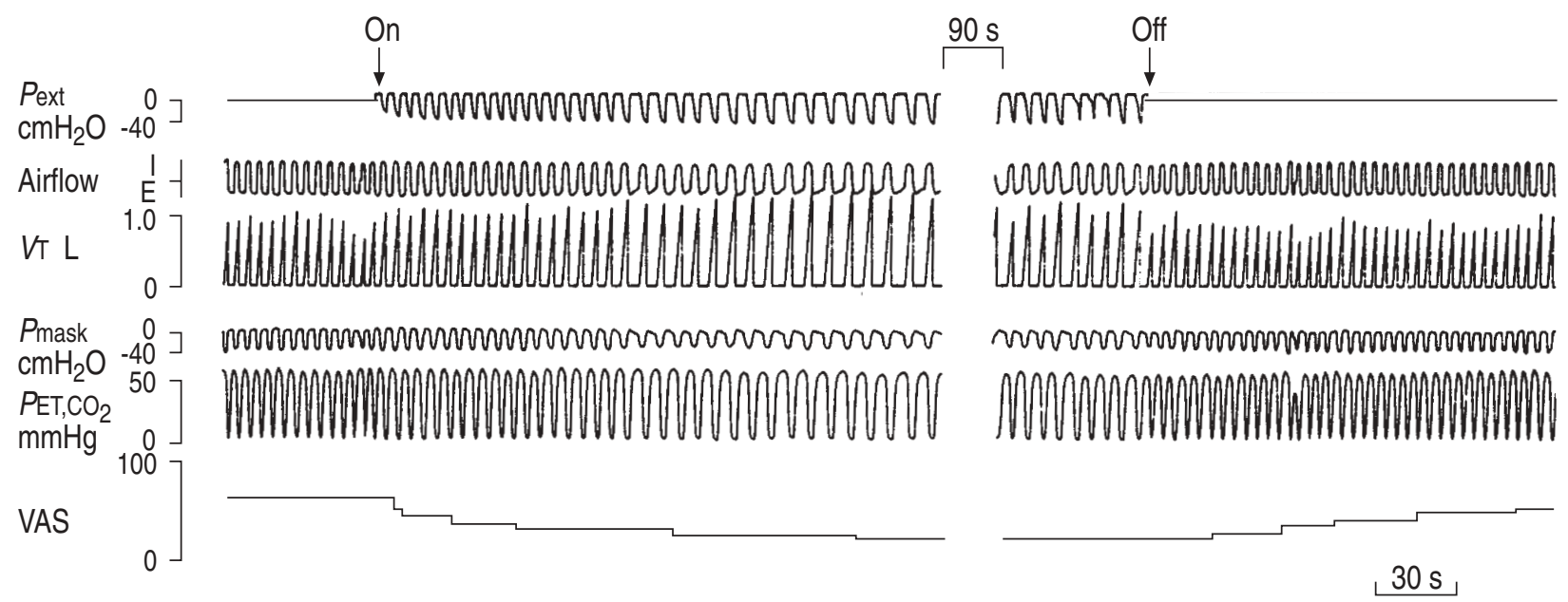

Fig. 2. - Experimental records illustrating changes in breathing pattern and visual analogue scale (VAS) score in response to assisted ventilation during loaded breathing. Assisted ventilation was initiated and terminated at the points indicated. Pext: extrathoracic pressure; I: inspiration; E: expiration; $V$ T: tidal volume; $P$ mask: mask pressure; $P$ ET, $\mathrm{CO}_{2}$ : end-tidal carbon dioxide tension.

$[3,4,6]$. However, in these studies, negative pressure ventilation was applied in the control mode while fixing $t \mathrm{I}, t \mathrm{E}$, and $f \mathrm{R}$ to closely approximate the patient's spontaneous timing components. Such settings of the ventilator may cause asynchrony between patient and ventilator since persistence of active breathing during NPAV has been observed in patients with chronic obstructive lung disease [16]. In our study, we used a demand-type negative pressure ventilator with which the subjects had control of the ventilatory rate and inspiratory assist time. Similarly to noninvasive PS ventilation, this mode of ventilatory support is able to interact better with the mechanism that regulates the breathing pattern than the control mode, and thereby produce a better acceptance and comfort of the subject.

In our study we observed an increase in $V \mathrm{~T}$ and a decrease in $f \mathrm{R}$ during NPAV. This observation is in agreement with the findings of MACINTYRE [17], V V DE GRAAF et al. [18], and VIAL et al. [19] who demonstrated that PS ventilation

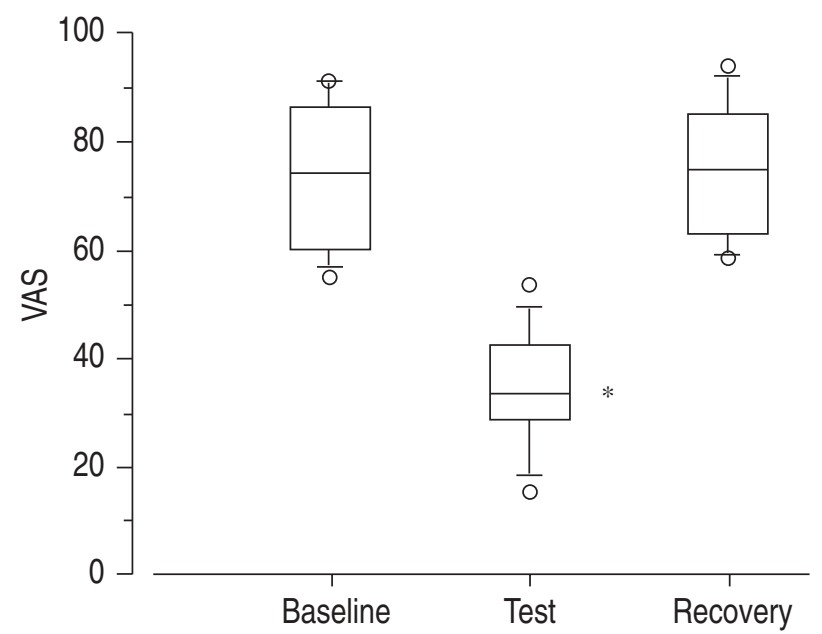

Fig. 3. - Changes in visual analogue scale (VAS) score in response to assisted ventilation. The box plot data shows the median, interquartile range and 10th and 90th percentiles. O: data outside the 10-90th percentile intervals. $*$ : $\mathrm{p}<0.01$, significantly different from the value during baseline. causes an increase in $V \mathrm{~T}$ and a decrease in $f \mathrm{R}$ in intubated patients with or without pre-existing pulmonary disease. These findings suggest that different methods of ventilatory support (PS versus NPAV) may not be a crucial factor in the determination of breathing patterns during assisted ventilation. MacInTyre [17] and VAN DE GraafF et al. [18] also observed that increasing the PS level did not change minute ventilation, carbon dioxide tension, or $\mathrm{pH}$ despite large changes in both rate and depth of breathing. Their observations are analogous to our findings that neither minute ventilation nor $P$ ET, $\mathrm{CO}_{2}$ changed during NPAV with assist-control mode. Although mechanisms that cause the characteristic breathing patterns consisting of increased $V \mathrm{~T}$ and decreased $f \mathrm{R}$ while maintaining minute ventilation and carbon dioxide tension at a constant level during assisted ventilation are not clear, these changes in breathing patterns may be partly associated with changes in sensation of respiratory discomfort. In this regard, it has been postulated that breathing pattern is partly behaviourally controlled in an effort to minimize the sensation of respiratory discomfort. For example, CHonan et al. [15] demonstrated that the spontaneously adopted pattern of breathing gives the minimum intensity of dyspnoea and that dyspnoea intensifies when ventilation is either voluntarily raised or lowered from the spontaneously adopted level. This concept of optimization of breathing patterns during addition of respiratory loading is also compatible with the hypothesis proposed by MEAD [20] that breathing patterns are adjusted to the level at which the work of breathing is minimal. In this regard, POON and GreENE [21] suggested that changes in the work of breathing may be sensed as changes in the sense of effort. TACK et al. [22] also showed that respiratory sensation changes as a function of both pressure and volume changes so that it is related to respiratory work.

In this study the oesophageal pressure was not measured so to what extent the work of breathing performed by the subjects decreased during NPAV could not be determined. Nevertheless, it is likely that assisted ventilation reduces the subject's inspiratory effort and work of breathing due to mechanical unloading of the respiratory muscles. Such reductions may establish a new spontaneously 
adopted pattern of breathing that gives the minimum intensity of dyspnoea. The resulting breathing pattern is thought to be the one which supplies the necessary alveolar ventilation for the minimum amount of muscle work. It may be possible that minute ventilation during assisted ventilation could be higher than the observed value so that the increased minute ventilation could considerably reduce arterial carbon dioxide tension or PET, $\mathrm{CO}_{2}$. However, this never occurred in this or other studies [17-19], indicating that behavioural control of breathing may prevail over chemical control of breathing in the presence of dyspnoea. Thus, although chemical control of breathing plays an important role in maintaining blood gas homeostasis, there may be certain circumstances where the body is able to tolerate hypercapnia while minimizing respiratory discomfort rather than maintain a very high level of respiratory muscle force output.

In this study, changes in the level of dyspnoea during NPAV could not have been caused by changes in chemical drive since $P$ ET, $\mathrm{CO}_{2}$ was maintained at a constant level and the experiment was performed under hyperoxia. Although the relief of dyspnoea observed during NPAV in this study is probably owing mainly to the reduced inspiratory effort and work of breathing, the possible influences from pulmonary stretch receptors and/or chest wall mechanoreceptors in the relief of dyspnoea during NPAV with the assist-control mode should also be considered. NPAV with the assist-control mode may stimulate these receptors inphase with inspiration by compulsory expansion of the chest wall. Since there is much evidence to suggest that afferent information from the lung and/or chest wall modifies the intensity of dyspnoea by inhibitory feed back [23-26], it is likely that the observed relief of dyspnoea during NPAV with the assist-control mode is partly due to stimulation of these receptors coinciding with inspiration. In this regard, it has been postulated that there may be a certain central gating mechanism that operates in relation to the sensation of dyspnoea [27]. In accordance with this postulation, sensation of dyspnoea may be alleviated when afferent information from the lung and/or chest wall matches the central operating phase. Thus, the marked relief of dyspnoea observed during NPAV with the assist-control mode may be due to in-phase stimulation of the lung and/ or chest wall mechanoreceptors, whereas the lack of beneficial effect of NPAV with the control mode may be associated with out-of-phase stimulation of these receptors. It is also noteworthy that stimulation of these receptors may directly contribute to the observed changes in breathing pattern during NPAV with assist-control mode through the reflex mechanism [28].

In addition, the decrease in the sensation of dyspnoea may be associated with the possible increase in end-expiratory lung volume during NPAV. However, the increase in end-expiratory lung volume causes mechanical disadvantage of the inspiratory muscles, and thereby increases inspiratory work, which may in turn intensify the dyspnoeic sensation. In fact, the work of KІкисні et al. [29] showed that the sensation of dyspnoea increases with an increase in end-expiratory lung volume during severe inspiratory loading in healthy subjects. Therefore, it is unlikely that the observed decrease in the dyspnoeic sensation during NPAV is due to the increase in end-expiratory lung volume.
The role of negative pressure assisted ventilation in clinical situations, particularly when the treatment of severe dyspnoea is needed, remains to be explored. Although negative pressure ventilation with control mode has been shown to be of no value at all when used with the aim of resting the respiratory muscles in patients with stable chronic obstructive pulmonary disease [6], the efficacy of negative pressure assisted ventilation with the assist-control mode in patients with pulmonary disease has not been evaluated. Assuming that the effect of negative pressure assisted ventilation with the assist-control mode on dyspnoea is comparable with that achieved with pressure support ventilation and that negative pressure assisted ventilation has several advantages attributed to lack of wearing a nasal or facial mask over pressure support ventilation, negative pressure assisted ventilation with the assist-control mode may become the preferred technique in relief of severe dyspnoea in patients with pulmonary disease, particularly during respiratory distress from acute exacerbations of chronic pulmonary diseases. Further studies addressing the efficacy of negative pressure assisted ventilation in terminally ill patients with severe dyspnoea are definitely needed. If the improvement in the intensity of dyspnoea could be obtained with negative pressure assisted ventilation with the assist-control mode even during a short period, there would be a place for this treatment since the relief of suffering should be the primary goal of therapy in these patients.

\section{References}

1. Bach JR, Alba A, Bohatiuk G, Saporito L, Lee M. Mouth intermittent positive pressure ventilation in the management of postpolio respiratory insufficiency. Chest 1987; 91: 859-864.

2. Gutierrez M, Beroiza T, Contreras G, et al. Weekly cuirass ventilation improves blood gases and respiratory muscle strength in patients with chronic air-flow limitation and hypercarbia. Am Rev Respir Dis 1988; 138: 617-623.

3. Zibrak JD, Hill NS, Federman EC, Kwa SL, O'Donnell C. Evaluation of intermittent long-term negative-pressure ventilation in patients with severe chronic obstructive pulmonary disease. Am Rev Respir Dis 1988; 138: 151-154.

4. Belman MJ, Soo Hoo GW, Kuei JH, Shadmehr R. Efficacy of positive $v s$ negative pressure ventilation in unloading the respiratory muscles. Chest 1990; 98: 850-856.

5. Nava S, Ambrosino N, Zocchi L, Rampulla C. Diaphragmatic rest during negative pressure ventilation by pneumowrap. Chest 1990; 98: 857-865.

6. Shapiro SH, Ernst P, Gray-Donald K, et al. Effect of negative pressure ventilation in severe chronic obstructive pulmonary disease. Lancet 1992; 340: 1425-1429.

7. Leger P, Bedicam JM, Cornette A, et al. Nasal intermittent positive pressure ventilation. Chest 1994; 105: 100105.

8. Wysocki M, Tric L, Wolff MA, Millet H, Herman B. Noninvasive pressure support ventilation in patients with acute respiratory failure. Chest 1995; 107: 761-768.

9. Cowcher K, Hanks GW. Long-term management of respiratory symptoms in advanced cancer. J Pain Symptom Manage 1990; 5: 341-344.

10. Maltais F, Reissmann H, Gottfried SB. Pressure support reduces inspiratory effort and dyspnea during exercise in chronic airflow obstruction. Am J Respir Crit Care Med 1995; 151: 1027-1033. 
11. Brochard L, Isabey D, Piquet J, et al. Reversal of acute exacerbations of chronic obstructive lung disease by inspiratory assistance with a face mask. N Engl J Med 1990; 323: $1523-1530$.

12. Brochard L, Mancebo J, Wysocki M, et al. Noninvasive ventilation for acute exacerbations of chronic obstructive pulmonary disease. N Engl J Med 1995; 333: 817-822.

13. Carrey Z, Gottfried SB, Levy RD. Ventilatory muscle support in respiratory failure with nasal positive pressure ventilation. Chest 1990; 97: 150-158.

14. Murray MJ, Gay PC. Noninvasive ventilation. Int Anesthesiol Clin 1997; 35: 45-64.

15. Chonan T, Mulholland MB, Altose MD, Cherniack NS. Effects of changes in level and pattern of breathing on the sensation of dyspnea. J Appl Physiol 1990; 69: 12901295.

16. Rodenstein DO, Stanescu DC, Cuttita G, Liistro G, Veriter $\mathrm{C}$. Ventilatory and diaphragmatic EMG responses to negative-pressure ventilation in airflow obstruction. $J$ Appl Physiol 1988; 65: 1621-1626.

17. MacIntyre NR. Respiratory function during pressure support ventilation. Chest 1986; 89: 677-683.

18. Van de Graaff WB, Gordey K, Dornseif SE, et al. Pressure support, changes in ventilatory pattern and components of the work of breathing. Chest 1991; 100: 1082-1089.

19. Viale JP, Annat GJ, Bouffard YM, Delafosse BX, Bertrand OM, Motin JP. Oxygen cost of breathing in postoperative patients: pressure support ventilation $v s$ continuous positive airway pressure. Chest 1988; 93: 506-509.

20. Mead J. Control of respiratory frequency. J Appl Physiol 1960; 15: 325-336.
21. Poon CS, Greene JG. Control of exercise hyperpnea during hypercapnia in humans. J Appl Physiol 1985; 59: 792-797.

22. Tack M, Altose MD, Cherniack NS. Effects of aging on sensation of respiratory force and displacement. $J$ Appl Physiol 1983; 55: 1433-1440.

23. Chonan T, Mulholland MB, Cherniack NS, Altose MD. Effect of voluntary constraining of thoracic displacement during hypercapnia. J Appl Physiol 1987; 63: 1822-1828.

24. Manning HL, Basner R, Ringler J, et al. Effect of chest wall vibration on breathlessness in normal subjects. $J$ Appl Physiol 1991; 71: 175-181.

25. Flume PA, Eldridge FL, Edwards LJ, Houser LM. Relief of distress of breathholding: separate effects of expiration and inspiration. Respir Physiol 1995; 101: 41-46.

26. Sibuya M, Yamada M, Kanamaru A, et al. Effect of chest wall vibration on dyspnea in patients with chronic respiratory disease. Am J Respir Crit Care Med 1994; 149: $1235-1240$.

27. Homma I, Obata T, Sibuya M, Uchida M. Gate mechanism in breathlessness caused by chest wall vibration in humans. J Appl Physiol 1984; 56: 8-11.

28. Younes MK, Remmers JE. Control of tidal volume and respiratory frequency. In: Hornbein TF, ed. Regulation of Breathing, Part I. New York, Marcel Dekker, 1981; pp. 621-671.

29. Kikuchi Y, Hida W, Chonan T, Shindoh C, Sasaki H, Takishima T. Decrease in functional residual capacity during inspiratory loading and the sensation of dyspnea. J Appl Physiol 1991; 71: 1787-1794. 